\title{
COMUNICACION PRELIMINAR SOBRE UN CASO DE AGENESIA DE VAGINA CON DOBLE UTERO UNICORNE
}

\author{
Doctor Joaquín Luna Uribe
}

Hemos querido aprovechar la oportunidad de este V Congreso de Obstetricia y Ginecología para presentar este caso de agenesia de vagina con doble útero unicorne, en el que empleamos para la elaboración de la vagina el método de doble tunelización de Sheares; y al encontrarnos en la laparotomía con un doble útero resolvimos emplear una modificación de la tuboimplantación uterina de Strassmann, que este autor ideó para tratar los casos de atresia de la cavidad uterina. Como último paso, conseguimos abocar la cavidad uterina a la neovagina formada, y contamos con el éxito de tener, en la actualidad, una mujer que está menstuando regularmente sin cólicos desde hace 7 meses.

Se trata de una paciente soltera, 16 años de edad, con historia clínica $N^{0}$ 203.094, del Hospital de la Samaritana de Bogotá. Nos consultó por primera vez en mayo 30 de 1962, por presentar dolores cólicos localizados hacia el hipogastrio, que se venían presentando clínicamente desde los 12 años, cuando comenzó su desarrollo puberal; pero no ha presentado en ninguna oportunidad descarga de tipo menstrual.

$\mathrm{Al}$ examen nos encontramos con una paciente bien desarrollada, en cuanto a sus caracteres sexuales secundarios.

Al examen ginecológico encontramos implantación pilosa en el monte de venus normal; vulva de características normales; himen rudimentario; foseta navicular excavada.

Tacto rectal, no se aprecia vagina; no hay hematocolpo; cuerpo de matriz en sinistro posición, discretamente globoso y duro; no se aprecian claramente estructuras correspondientes a cuello uterino.

Por medio de la anamnesis y de la observación cuidadosa se llegó al diagnóstico de criptomenorrea por atresia de vagina, con una masa pélvica posiblemente correspondiente a útero. En esta situación consideramos que el método que menos complicaciones inmediatas nos daría la construcción de la vagina era el de Sheares, el cual no exige la práctica de injertos, dado que, según este autor, lo ha comprobado en 
18 casos; la cavidad vaginal se epiteliza satisfactoriamente, a expensas de probables islotes de restos embrionarios de los canales de Muller, que estarían localizados en los sitiso por donde se excavan los túneles en el espacio vésico-rectal.

El autor hace hincapié, además, en que con esta técnica existen menos problemas de estenosis del canal preformado, puesto que se reseca el rafé mediano existente entre los dos túneles practicados, lo cual nos daría mayores garantías para la permeabilidad de la vagina, ya que se trata de una paciente soltera.

Respecto a la parte abdominal, se practicó laparotomía por incisión de Pfannestiel. Se encuentra matriz en siniestro posición y de un tamaño correspondiente a lo normal, al parecer sin cuello y con un foco de endometriosis en un fondo protegido por múltiples adherencias del epiplón mayor y formación de cavidades quísticas llenas de líquido sanguíneo achocolatado, que se rompen en las maniobras de liberación. Resección del foco de endometriosis con las adherencias epiploicas, practicando epiploectomía parcial. La trompa izquierda, el ovario y el ligamento redondo se insertan en el sitio usual del útero descrito; del lado derecho se encuentra una matriz rudimentaria, que se continuúa hacia abajo con una formación cordonal larga y hacia arriba con una trompa de aspecto infantil; el ovario derecho, de caracteres macroscópicos en situación normal. En ambos ovarios se aprecian cuerpos amarillos y albus de características usuales.
En este momento, cuando nos encontramos ante un útero más o menos bien desarrollado y otro rudimentario, tuvimos la idea de practicar la implantación del útero rudimentario con su cuello rudimentario dentro del útero más desarrollado, basándonos en las observaciones de Strassman. Lo que más nos movió a ensayar esta idea fue el hecho de que nos encontramos con un útero unicorme bien desarrollado, pero con ausencia de cuello, y pensamos que, si en el caso de la atresia uterina, la implantación de la trompa dentro del útero hace que la cavidad se reconstruya con el cuello rudimentario que teníamos, al pasarlo por la uterotomía inferior y fijarlo a la vagina, el canal se mantendría permeable para las menstruaciones posteriores.

Para conseguir esto, practicamos una uterotomía en el fondo del útero izquierdo, resecando un cono hasta llegar a la cavidad uterina, de donde sale escasa cantidad de sangre antigua. Se abre un ojal en el espacio recto-vesical en el sitio en donde debiera estar el cuello uterino, y no encontrándose estructura que lo recuerde se practica otra nueva uterotomía en el polo inferior de la matriz.

Se desinserta el cuello del útero rudimentario y se individualiza del ligamento redondo, el cual hace un recorrido paralelo al útero y cuello rudimentario.

Se abre por la mitad el cuello rudimentario y se repara cada colgajo con puntos de seda.

Se introduce una pinza por la uterotomía inferior, hasta que aparezca en la uterotomía superior, se toman los 
reparos de los colgajos del cuello rudimentario y se retira nuevamente la pinza para introducir el útero rudimentario entre el útero más desarrollado. Se fija el útero rudimentario a los bordes de la uterotomía superior con puntos de seda, separados, y se peritoniza. Se fija con puntos separados el ligamento redondo derecho a la cara anterior $y$ borde lateral derecho del útero más desarrollado. Exteriorizados los colgajos del útero rudimentario por la histerotomía inferior, se fijan a los bordes anterior y posterior.

Por el orificio superior de la neovagina (situado en el espacio recto-vesical) se introducen los colgajos del cuello rudimentario y se fijan, el anterior a la pared anterior de la neovagina $y$ el posterior a la pared posterior.

Se fija con seda el contorno naritoneal de la neovagina al pols inferior del útero y se peritoniza.

Para fortuna de todos, las consideraciones que nos hicimos y las técnicas que empleamos nos dieron resultados satisfactorios, como lo demuestran las citologías vaginales tomadas el 16 de octubre y el 6 de febrero de 1962 y 1963 (respectivamente y que copiamos a continuación):

Citología Nọ 62-449, según el orden del I. C. S. S.

Paciente: L. B. "Los frotis muestran muchos glóbulos rojos y acúmulos polimorfonucleares. Se observa célula, en su mayoría precornificadas y parabasales del cérvix".

(Fdo.), doctor Pablo García I.

Citología Nọ 63-62, según el orden del I. C. S. S.
Paciente: L. B. "Las preparaciones son casi ilegibles, pues constituyen en su totalidad frotis de sangre".

"Sin embargo se observan elementos inflamatorios, escasísimas células epidermoides y algunas otras aparentemente de tipo endocervical".

Posteriormente, debido a estenosis del tercio superior de la vagina y masa anexial derecha, se practicó un último acto quirúrgico con dos partes: una primera por vía vaginal, ampliando el tercio superior de la vagina, practicando dos túneles laterales y obteniendo colgajos de mucosa vaginal de los tercios medios e inferior para tapizar el tercio superior, y una segunda parte por laparotomía, encontrando la matriz de aspecto normal, las trompas de tipo hipoplásico; en el ovario derecho existe un quiste de retención; se encuentra un foco al parecer de endometriosis hacia la parte posterior de la matriz, al cual se atribuyen los dolores periódicos que se presentaba la paciente antes de su último ingreso.

se libera el polo inferior de la matriz del fondo del saco peritoneal posterior. Se permeabiliza la histerotomía en este sitio y se restablece la comunicación de la cavidad uterina con la vagina.

El 29 de abril de 1963 asiste a la consulta, presentando descargo sanguínea abundante, que al aspecto es de tipo menstrual. No ha tenido cólico hipogástrico. Se toma muestra para investigación citológica.

La vagina, en el tercio superior, permite únicamente el paso de un dedo. 
El estudio citológico No C-20-63 dice:

Nombre de la paciente: L. B.

Observaciones:

El frotis muestra el aspecto usual para el período menstrual. Se ven pequeños grupos de células en endometriales descamadas de aspecto normal. (Fdo.), doctor Armando Santamaría.

La paciente continúa asistiendo a controles periódicos. Se ha insistido en la necesidad de aplicar un tubo de ensayo en la vagina para evitar la estenosis del tercio superior, que tiene tendencia a estrecharse.

Las últimas menstruaciones se han presentado de características normales, por tres días de duración, sin dolores cólicos, así:

26 de mayo

21 de junio

19 de julio

16 de agosto

16 de septiembre.

El 15 de octubre de 1963 se practica histerografía; se aprecia cavidad uterina, que por su capacidad no se observa completamente llena por el medio de contraste inyectado -10 centímetros cúbicos-; estenosis discreta en el tercio superior de la vagina. No se obtuvo paso del medio de contraste a las trompas.

Los resultados obtenidos en esta paciente nos indican un claro éxito, puesto que ella actualmente menstrúa con normalidad, a partir de los 9 meses de practicada la primera operación. Las citologías efectuadas nos demuestran la presencia de cuello uterino y descamación menstrual de tipo normal. La histerosalpingografía nos confirma la existencia y permeabilidad de los canales uterinos, cervical y vaginal.

Creemos importante que estas pacientes, con malformaciones congénitas del útero, no deben ser mutiladas en uno cualquiera de sus elementos, salvo necesidad imperiosa por marcada patología de alguno de sus órganos; pues posiblemente con plastias en los cuerpos uterinos y abocamiento de este órgano a la vagina, ya sea ella natural o neoformada, tendremos la posibilidad de obtener que estas mujeres no se sientan diferentes a sus compañeras, y lleguen a ostentar esa divisa de la feminidad que es la menstruación. 